\title{
Low glycaemic index diet and disposition index in type 2 diabetes (the Canadian trial of Carbohydrates in Diabetes): a randomised controlled trial
}

\author{
T. M. S. Wolever • C. Mehling • J.-L. Chiasson • \\ R. G. Josse • L. A. Leiter • P. Maheux • \\ R. Rabasa-Lhoret $\cdot$ N. W. Rodger $\cdot$ E. A. Ryan
}

Received: 21 May 2008 / Accepted: 19 June 2008 / Published online: 22 July 2008

(C) Springer-Verlag 2008

\begin{abstract}
Aims/hypothesis We recently found that oral glucose tolerance over 1 year in type 2 diabetic patients declined to a significantly lesser degree on a low-glycaemic-index than on a reduced-carbohydrate diet. Here, we examined whether that finding was associated with an improvement in disposition index, an index of beta cell function defined
\end{abstract}

Electronic supplementary material The online version of this article (doi:10.1007/s00125-008-1093-x) contains supplementary material, which is available to authorised users.

T. M. S. Wolever $(\bowtie) \cdot$ C. Mehling $\cdot$ R. G. Josse $\cdot$ L. A. Leiter Department of Nutritional Sciences,

150 College St,

Toronto, ON, Canada, M5S 3E2

e-mail: thomas.wolever@utoronto.ca

T. M. S. Wolever $\cdot$ R. G. Josse $\cdot$ L. A. Leiter

Department of Medicine, St Michael's Hospital,

University of Toronto,

Toronto, ON, Canada

J.-L. Chiasson · R. Rabasa-Lhoret

Research Center (CHUM) Hôtel-Dieu de Montréal,

University of Montréal,

Montreal, QC, Canada

P. Maheux

Department of Medicine, University of Sherbrooke,

Sherbrooke, QC, Canada

N. W. Rodger

Department of Medicine, St Joseph's Health Center,

University of Western Ontario,

London, ON, Canada

E. A. Ryan

Department of Medicine, University of Alberta,

Edmonton, AB, Canada as the product of insulin sensitivity and insulin secretion. Since this is a report of secondary analysis on a previously published trial, the results should be considered as hypothesis-generating.

Methods Type 2 diabetic patients treated by diet alone $(n=162)$ were randomised by computer to high-carbohydrate/highglycaemic index (High-GI, $n=52$ ), high-carbohydrate/lowglycaemic index (Low-GI, $n=56$ ) or low-carbohydrate/ high-monounsaturated-fat (Low-CHO, $n=54$ ) diets for 1 year in a multi-centre, parallel-design clinical trial conducted at University teaching hospitals. At baseline and at 3, 6 and 12 months participants underwent $75 \mathrm{~g}$ OGTTs; 27 participants dropped out or were excluded. Indices of insulin sensitivity, insulin secretion and disposition index, derived from the OGTT, were compared among diets. Those assessing the outcomes were blinded to group assignment.

Results Neither muscle insulin sensitivity index nor insulinogenic index differed significantly among diets. However, a significant time $\times$ diet interaction existed for disposition index (muscle insulin sensitivity index $\times$ insulinogenic index) $(p=0.036)$. After 3 months, disposition index tended to be higher on Low-CHO than on Low-GI diets, namely by $0.07 \mathrm{~h}^{-1}(95 \% \mathrm{CI}-0.04,0.18)$. However, by 12 months this reversed and disposition index became higher on LowGI than on Low-CHO, namely by $0.12 \mathrm{~h}^{-1}(0.01,0.23 ; p<$ 0.05 , baseline disposition index $0.23 \mathrm{~h}^{-1}$ ). There were no important adverse effects associated with the treatments.

Conclusions/interpretation These results suggest that, in patients with type 2 diabetes on diet alone, a Low-GI diet for 1 year increases disposition index, an index of beta cell function, compared with a Low-CHO diet.

Trial registration: ISRCTN81151522 
Funding: Canadian Institutes of Health Research (CIHRMCT-44205)

Keywords Beta cell function - Dietary carbohydrates . Humans · Insulin secretion · Insulin sensitivity · Monounsaturated fatty acids $\cdot$ Nutrition

\begin{tabular}{|c|c|}
\hline \multicolumn{2}{|c|}{ Abbreviations } \\
\hline CVD & cardiovascular disease \\
\hline High-GI & high-carbohydrate/high-glycaemic-index diet \\
\hline Low-CHO & low-carbohydrate/high-MUFA diet \\
\hline Low-GI & high-carbohydrate/low-glycaemic-index diet \\
\hline HIR & hepatic insulin resistance index \\
\hline HOMA-b & $\begin{array}{l}\text { homeostasis model assessment for beta cell } \\
\text { function }\end{array}$ \\
\hline HOMA-r & $\begin{array}{l}\text { homeostasis model assessment for insulin } \\
\text { resistance }\end{array}$ \\
\hline $2 \mathrm{hPCG}$ & $\begin{array}{l}\text { plasma glucose concentration at } 2 \mathrm{~h} \text { after } 75 \mathrm{~g} \\
\text { OGTT }\end{array}$ \\
\hline MIS $\times$ II & disposition index \\
\hline MUFA & monounsaturated fatty acid \\
\hline NSAID & non-steroidal anti-inflammatory drug \\
\hline
\end{tabular}

\section{Introduction}

We recently compared the effects of altering the amount vs the glycaemic index of dietary carbohydrate for 1 year in type 2 diabetic patients being treated by diet-alone on overall glycaemic control and the plasma glucose concentration at $2 \mathrm{~h}$ after $75 \mathrm{~g}$ OGTT (2hPCG) [1]. Although $\mathrm{HbA}_{1 \mathrm{c}}$ did not differ among diets, the results showed a significant adaptation in the OGTT. At 3 months 2hPCG was significantly lower than baseline on the low-carbohydrate but not on the low-glycaemic-index diet. However, by 1 year $2 \mathrm{hPCG}$ had increased significantly more on the lowcarbohydrate than on the low-glycaemic-index diet. Here, we report the results of secondary analyses of the OGTT results, conducted to investigate possible mechanisms of this long-term adaptation in 2hPCG.

Blood glucose homeostasis depends on a balance between insulin sensitivity and insulin secretion. In normal individuals, between- and within-individual variations in insulin sensitivity are compensated for by reciprocal changes in insulin secretion $[2,3]$. The product of insulin sensitivity and insulin secretion is the disposition index [3], which is considered to be a measure of beta cell function. Type 2 diabetes occurs when reduced insulin sensitivity cannot be compensated for by increased insulin secretion, i.e. reduced disposition index $[4,5]$. The relentless progression of type 2 diabetes is thought to be due to a progressive decline of disposition index $[5,6]$.
The dietary management of type 2 diabetes is controversial, particularly with respect to dietary carbohydrate. Ideally, dietary treatment would increase disposition index, either by improving insulin sensitivity or insulin secretion or both. Low-carbohydrate, high-monounsaturated-fattyacids (MUFA) [7, 8], or low-glycaemic-index diets [9], may improve insulin sensitivity in individuals with type 2 diabetes, but little is known about the effects of such diets on beta cell function in type 2 diabetes. Furthermore, the studies cited were of short duration (2-5 weeks) and it is not known whether the short-term effects persist over a longer period of time. Since use of low-glycaemic-index carbohydrate foods for 4 months increased disposition index in participants with impaired glucose tolerance [10], we hypothesised that a low-glycaemic-index diet would increase disposition index in patients with type 2 diabetes. Thus, the purpose of this paper was to compare the effects of a high-carbohydrate/low-glycaemic-index diet (Low-GI) with those of low-carbohydrate/high-MUFA (Low-CHO) and high-carbohydrate/high-glycaemic-index (High-GI) diets for 1 year on indices of insulin sensitivity, insulin secretion and disposition index derived from fasting and postprandial plasma glucose and insulin concentrations during OGTT in participants with type 2 diabetes who were being treated by diet alone. Because this is a secondary analysis, the results should be considered to be hypothesis-generating.

\section{Methods}

Study centres The study was carried out on an outpatient basis at five university-affiliated teaching hospitals across Canada. The protocol was approved by the human ethics review committee at each participating institution and all participants consented to participate.

Participants Men or non-pregnant women who had type 2 diabetes (fasting glucose $\geq 7.0 \mathrm{mmol} / 1$ or $2 \mathrm{hPCG} \geq$ $11.1 \mathrm{mmol} / \mathrm{l}$ within 2 months of randomisation) managed by diet alone were recruited. Participants were aged 35 to 75 years, had $\mathrm{HbA}_{1 \mathrm{c}} \leq 130 \%$ upper limit of normal, BMI 24 to $40 \mathrm{~kg} / \mathrm{m}^{2}$, were not using insulin or any hypoglycaemic or anti-hyperglycaemic medication and were otherwise generally healthy. Detailed inclusion and exclusion criteria and the rationale for the sample size are reported elsewhere [1].

Dietary intervention After being identified, participants handed in a 3-day food record and underwent a baseline OGTT. A dietitian provided dietary advice with the aim of attaining $55 \%$ of energy from carbohydrate, $15 \%$ from protein and $30 \%$ from fat, consisting of $8 \%$ to $9 \%$ saturated fatty acids, $8 \%$ to $10 \%$ polyunsaturated fatty acids and $15 \%$ 
to $20 \%$ MUFA. Two weeks later participants $(n=162)$ were randomly assigned as previously described [1] to one of three diets: High-GI, Low-GI or Low-CHO. Blocks of various sizes were used to enhance allocation concealment. Treatment assignments were sealed in sequentially numbered opaque envelopes kept by a person not involved with the study. Further OGTTs were performed at 3, 6 and 12 months after randomisation, during which participants drank $75 \mathrm{~g}$ glucose solution (Ratiopharm, Mississauga, ON, Canada) within $5 \mathrm{~min}$, with blood samples obtained in the fasting state and at 30,60 and 120 min after starting the drink.

The dietary intervention was effected by instructing participants to consume an individually prescribed amount of key foods each day, chosen from a list of 16 to $21 \mathrm{key}$ foods per diet and provided free of charge. A dietitian advised participants how to incorporate the key foods into their diets to avoid weight gain. The High-GI and Low-GI diet key foods were starchy foods whose glycaemic index we had determined and prescribed such that their carbohydrate provided $20 \%$ to $25 \%$ of energy. The Low-CHO diet key foods consisted of oils, spreads, nuts and other foods low in saturated fatty acids and high in MUFA and reported to reduce diabetes and cardiovascular disease (CVD) risk and/or to reduce blood lipids. They were prescribed to replace carbohydrate normally consumed with a view to increasing total fat intake by about $10 \%$. Details about the amounts and types of key foods consumed are reported elsewhere [1]. Food records were made for a period of 3 days at $1,3,6,9$ and 12 months after randomisation.

Laboratory measurements and calculations Blood samples were analysed and the data managed centrally by individuals who were unaware of the treatment allocations of the participants. $\mathrm{HbA}_{1 \mathrm{c}}$ was analysed by HPLC (Diamat HPLC; Bio-Rad Laboratories Canada, Mississauga, ON, Canada), plasma glucose by a hexokinase method and insulin by electrochemiluminescence immunoassay (Roche Diagnostics, Mannheim, Germany). The nutrient composition of the diets was assessed using an in-house programme as previously described [1]. As used here, the term 'carbohydrate' refers to available carbohydrate, defined as total carbohydrate minus dietary fibre.

Several models have been described for estimating insulin sensitivity and secretion from plasma glucose and insulin concentrations during the OGTT. We used the homeostasis model assessment for insulin resistance (HOMA-r) [11], $\left(\left[\mathrm{G}_{0} \times \mathrm{I}_{0}\right] / 135\right.$, where $\mathrm{G}_{0}$ is fasting glucose in $\mathrm{mmol} / \mathrm{l}$ and $\mathrm{I}_{0}$ is fasting insulin in pmol/l) and the hepatic insulin resistance index (HIR) and muscle insulin sensitivity index [12]. HIR is $\mathrm{G}_{0-30}(\mathrm{AUC}) \times \mathrm{I}_{0-30}$ (AUC) where $\mathrm{G}_{0-}$ ${ }_{30}($ AUC $)$ and $\mathrm{I}_{0-30}$ (AUC) are the total glucose and insulin response AUCs respectively between 0 and $30 \mathrm{~min}$. Muscle insulin sensitivity index is the rate of decay of plasma glucose from its peak to its nadir during the OGTT divided by mean plasma insulin during the OGTT. If glucose continued to rise throughout the $2 \mathrm{~h}$ period of the OGTT, the slope was taken to be zero.

For basal insulin secretion, we used HOMA for beta cell function (HOMA-b) [11]. The Stumvoll first-phase measure of insulin secretion [13] was not used because $~ 50 \%$ of the values were negative. Instead we used insulinogenic index [14], defined as the rise in insulin divided by the rise in glucose from 0 to $30 \min \left(\Delta I_{0-30} / \Delta G_{0-30}\right)$. Any negative values obtained were taken to be zero. The disposition index was calculated as muscle insulin sensitivity index $\times$ insulinogenic index $(\mathrm{MIS} \times \mathrm{II})$.

Endpoints The results for the primary endpoint of the study $\left(\mathrm{HbA}_{1 \mathrm{c}}\right)$ and for the secondary endpoints of plasma glucose and insulin concentrations in the fasting state and $2 \mathrm{~h}$ after the OGTT have been published elsewhere [1]. The results for plasma glucose and insulin concentrations at 30 and $60 \mathrm{~min}$ after the OGTT, as well as indices of insulin sensitivity and secretion derived from the OGTT, have not been published before. Insulinogenic index was declared as a secondary endpoint when the study was registered, but HOMA-r, HIR, muscle insulin sensitivity index, HOMA-b and MIS $\times$ II were calculated post hoc as secondary analyses.

Statistics Data were analysed on an intent-to-treat basis for participants with OGTT results available at 6 and/or 12 months. Results are presented as mean \pm SEM or mean $(95 \% \mathrm{CI})$. Plasma glucose and insulin concentrations were subjected to ANOVA examining for the main effects of diet, time $(0-120 \mathrm{~min})$ and visit $(0-12$ months $)$ and their interactions [15]. HOMA-r, HOMA-b, HIR, muscle insulin sensitivity index, insulinogenic index and MIS $\times$ II at 3, 6 and 12 months were adjusted for sex and baseline value and the residuals analysed by ANOVA for the main effects of diet and time (3-12 months) and the $\operatorname{diet} \times$ time interaction, with the error degrees of freedom being reduced by the number of imputed values. When significant interactions were found, the differences between individual means were tested using Tukey's test to adjust for multiple comparisons; the criterion of significance was two-tailed $p<0.05$. The primary endpoint of the study was $\mathrm{HbA}_{1 \mathrm{c}}$. Since all of the results reported here represent secondary endpoints or secondary analyses, we did not adjust the $p$ values for the multiple endpoints. For this reason, the findings should be considered to be hypothesisgenerating and requiring further confirmation.

\section{Results}

The flow chart for the study was published in the primary paper [1]. Participants $(n=162)$ were randomised from 
January 2002 to the end of October, 2003; for this paper, 25 participants were excluded because of insufficient data as follows: (1) OGTT at baseline $(n=11)$ or baseline and 3 months $(n=10)$ only; and (2) indices not calculable because blood samples were only available for fasting and $2 \mathrm{~h}(n=4)$. This left 137 participants with an OGTT at 6 and/or 12 months. Two participants were excluded because of outlying values for muscle insulin sensitivity index. One missing baseline OGTT was imputed as the mean of the three other values. Values missing at 3 or 6 months $(n=21)$ were imputed as the mean of the values before and after. Values missing at 12 months $(n=25)$ were replaced by the 6 month values (last value carried forward).

Baseline comparisons At baseline, there were no significant differences in glucose, insulin or indices of insulin sensitivity or secretion among diet groups; however, compared with women, men had significantly higher waist circumference, muscle insulin sensitivity index and MIS $\times$ II, and lower $2 \mathrm{~h}$ plasma insulin and insulinogenic index (Table 1). Records of concomitant medications used during the trial were available for 126 of the 135 participants included in this paper (93\%). Since all participants had type 2 diabetes treated by diet alone, none were taking any oral hypoglycaemic or anti-hyperglycaemic drug or insulin at baseline or during the trial. There were no significant differences among diet groups in the number of participants taking medications at baseline nor in the number of participants who changed dose during the trial for any of the 18 categories of concomitant medications (Electronic supplementary material [ESM] Table 1). Steroids used during the trial were all short courses as follows: (1) cortisone injection into a joint on one $(n=2)$ or two $(n=1)$ occasions; (2) topical prednisone for 2 to 3 weeks for dermatological conditions $(n=2)$; (3) inhaled prednisone for bronchitis for 6 weeks $(n=1)$; and (4) systemic prednisone for bronchitis for $6(n=1)$ or 9 days $(n=1)$. Participants taking aspirin had lower HOMA-r at baseline than those who did not, i.e. 2.5 (95\% CI $2.1,3.0)$ vs $3.6(3.0,4.1 ; p=0.007)$. Participants who took non-steroidal anti-inflammatory drugs (NSAIDs) had higher insulinogenic index, i.e. $33(26,40)$ vs $25(21$, $29 ; p=0.044) \mathrm{pmol} / \mathrm{mmol}$, higher muscle insulin sensitivity index, $0.022(0.010,0.033)$ vs $0.010(0.007,0.013 ; p=$ 0.006) mmol pmol ${ }^{-1} \mathrm{~h}^{-1}$ and higher disposition index, 0.34 $(0.23,0.45)$ vs $0.19(0.14,0.25 ; p=0.009) \mathrm{h}^{-1}$ at baseline than those who did not. Participants taking nutritional supplements had higher insulinogenic index at baseline than those who did not, i.e. $31(25,36)$ vs $23(19,27 ; p=0.041)$ $\mathrm{pmol} / \mathrm{mmol}$. Participants on statins had higher insulinogenic index at baseline than those who did not, i.e. $31(26,36)$ vs $22(18,26 ; p=0.009) \mathrm{pmol} / \mathrm{mmol}$.

Dietary composition Energy and protein intakes did not change significantly on the High-GI, Low-GI and LowCHO diets (Table 2). Total fat intake decreased from baseline on the High-GI and Low-GI diets and increased on Low-CHO; about $66 \%$ of the increase in fat on Low-CHO was accounted for by MUFA and the remainder was accounted for by polyunsaturated fat. Intake of saturated fat fell slightly but significantly on all three diets. Carbohydrate intake increased from baseline on the HighGI and Low-GI diets and decreased on Low-CHO. Glycaemic index increased from baseline on High-GI, decreased on Low-GI and did not change on Low-CHO.

Table 1 Baseline variables at randomisation

\begin{tabular}{|c|c|c|c|c|c|}
\hline Variable & High-GI & Low-GI & Low-CHO & Men & Women \\
\hline$n$ (men:women) & $21: 20$ & $16: 30$ & $25: 23$ & $62: 0$ & $0: 73$ \\
\hline Age (years) & $59.8 \pm 1.2$ & $60.8 \pm 1.1$ & $58.8 \pm 1.3$ & $58.8 \pm 1.0$ & $60.6 \pm 0.9$ \\
\hline BMI $\left(\mathrm{kg} / \mathrm{m}^{2}\right)$ & $31.0 \pm 0.7$ & $31.1 \pm 0.8$ & $30.9 \pm 0.6$ & $30.3 \pm 0.5$ & $31.6 \pm 0.6$ \\
\hline Waist circumference $(\mathrm{cm})$ & $103 \pm 2$ & $99 \pm 2$ & $102 \pm 2$ & $105 \pm 1$ & $98 \pm 1^{*}$ \\
\hline $\mathrm{HbA}_{1 \mathrm{c}}$ & $0.061 \pm 0.001$ & $0.062 \pm 0.001$ & $0.062 \pm 0.001$ & $0.061 \pm 0.001$ & $0.062 \pm 0.001$ \\
\hline Fasting glucose $(\mathrm{mmol} / \mathrm{l})$ & $7.4 \pm 0.2$ & $7.0 \pm 0.1$ & $7.5 \pm 0.2$ & $7.4 \pm 0.2$ & $7.2 \pm 0.1$ \\
\hline 2hPCG (mmol/1) & $13.4 \pm 0.5$ & $13.5 \pm 0.5$ & $14.1 \pm 0.4$ & $13.3 \pm 0.4$ & $14.0 \pm 0.4$ \\
\hline Fasting insulin (pmol/1) & $62 \pm 4$ & $56 \pm 6$ & $53 \pm 5$ & $52 \pm 4$ & $61 \pm 4$ \\
\hline $2 \mathrm{~h}$ plasma insulin $(\mathrm{pmol} / \mathrm{l})$ & $391 \pm 36^{\mathrm{a}, \mathrm{b}}$ & $402 \pm 43^{\mathrm{a}}$ & $285 \pm 26^{\mathrm{b}}$ & $300 \pm 26$ & $404 \pm 31^{*}$ \\
\hline HOMA-r & $3.5 \pm 0.3$ & $3.0 \pm 0.4$ & $3.0 \pm 0.3$ & $2.8 \pm 0.2$ & $3.4 \pm 0.3$ \\
\hline HOMA-b & $57 \pm 5$ & $55 \pm 5$ & $48 \pm 4$ & $47 \pm 4$ & $58 \pm 4$ \\
\hline $\operatorname{HIR}\left(\mathrm{mmol} \times \mathrm{pmol} \mathrm{l}^{-2} \mathrm{~h}^{-2}\right)$ & $339 \pm 29$ & $305 \pm 36$ & $270 \pm 23$ & $274 \pm 24$ & $328 \pm 25$ \\
\hline Muscle insulin sensitivity index $\times 100\left(\mathrm{mmol} \mathrm{pmol}{ }^{-1} \mathrm{~h}^{-1}\right)$ & $1.41 \pm 0.36$ & $1.33 \pm 0.31$ & $1.29 \pm 0.26$ & $1.72 \pm 0.26$ & $1.00 \pm 0.23^{*}$ \\
\hline Insulinogenic index (pmol/mmol) & $28.5 \pm 3.0$ & $28.9 \pm 3.6$ & $22.4 \pm 2.0$ & $21.6 \pm 2.2$ & $30.6 \pm 2.5^{*}$ \\
\hline $\mathrm{MIS} \times \operatorname{II}\left(\mathrm{h}^{-1}\right)$ & $0.25 \pm 0.04$ & $0.25 \pm 0.05$ & $0.22 \pm 0.04$ & $0.29 \pm 0.04$ & $0.19 \pm 0.03 *$ \\
\hline
\end{tabular}

Values are means \pm SEM

${ }_{\mathrm{a}, \mathrm{b}} p<0.05$ for difference between diet group means with different superscript letters

$* p<0.05$ for difference between men and women 
Table 2 Composition of diets at baseline and on study diets

\begin{tabular}{|c|c|c|c|c|}
\hline Variable & Baseline & High-GI & Low-GI & Low-CHO \\
\hline Energy $(\mathrm{kJ} / \mathrm{d})$ & $7,770 \pm 180$ & $7,690 \pm 250$ & $7,610 \pm 240$ & $8,440 \pm 240$ \\
\hline Protein (\% energy) & $20 \pm 0.3$ & $20 \pm 0.5$ & $21 \pm 0.5$ & $19 \pm 0.4$ \\
\hline Total fat ( $\%$ energy) & $33 \pm 0.5$ & $30 \pm 0.7^{a *}$ & $27 \pm 0.8^{\mathrm{b} *}$ & $40 \pm 0.6^{\mathrm{C} *}$ \\
\hline Saturated fat (\% energy) & $11 \pm 0.3$ & $10 \pm 0.4^{*}$ & $8 \pm 0.8^{*}$ & $11 \pm 0.3^{*}$ \\
\hline Monounsaturated fat (\% energy) & $14 \pm 0.3$ & $12 \pm 0.4^{\mathrm{a} *}$ & $11 \pm 0.4^{\mathrm{b} *}$ & $18 \pm 0.3^{\mathrm{c} *}$ \\
\hline Polyunsaturated fat (\% energy) & $6 \pm 0.1$ & $6 \pm 0.2^{\mathrm{a} *}$ & $5 \pm 0.2^{\mathrm{a} *}$ & $8 \pm 0.2^{\mathrm{b} *}$ \\
\hline Carbohydrate ( $\%$ energy) & $44 \pm 0.6$ & $47 \pm 1^{\mathrm{a} *}$ & $52 \pm 1^{\mathrm{b} *}$ & $39 \pm 1^{\mathrm{c} *}$ \\
\hline Dietary fibre (g/d) & $22 \pm 0.6$ & $21 \pm 0.8^{\mathrm{a}}$ & $37 \pm 1.5^{\mathrm{b} *}$ & $23 \pm 0.8^{\mathrm{a}}$ \\
\hline Glycaemic index (\%) & $61 \pm 0.3$ & $63 \pm 0.4^{\mathrm{a} *}$ & $55 \pm 0.4^{\mathrm{b} *}$ & $60 \pm 0.5^{\mathrm{c}}$ \\
\hline Glycaemic load (g/d) & $126 \pm 2$ & $137 \pm 3^{\mathrm{a} *}$ & $133 \pm 3^{\mathrm{a}}$ & $110 \pm 2^{\mathrm{b}} *$ \\
\hline
\end{tabular}

Values are means \pm SEM

a,b,c $p<0.05$ for difference between means with different superscript letters ${ }^{*} p<0.05$ for difference from baseline

Thus, glycaemic load increased on High-GI and decreased on Low-CHO, but did not change significantly on Low-GI. Dietary fibre intake did not change on High-GI or Low$\mathrm{CHO}$, but increased significantly on Low-GI.

Adverse events, body weight and $H b A_{1 c}$ There were no important adverse effects associated with the treatments. As reported previously [1], body weight fell by $\sim 0.5 \mathrm{~kg}$ over the first 8 weeks, then rose steadily to $\sim 0.8 \mathrm{~kg}$ higher than at baseline by 12 months $(p=0.0005)$. Mean weight on Low-GI was $0.4 \mathrm{~kg}$ less than that on High-GI and Low$\mathrm{CHO}(p=0.062)$. The primary endpoint, $\mathrm{HbA}_{1 \mathrm{c}}$, rose from $\sim 0.061$ at baseline to $\sim 0.063$ after 12 months $(p<0.0001)$, but there was no significant difference among diets [1].
Glucose and insulin during OGTT There was a significant time $\times \operatorname{diet} \times$ visit interaction $(p=0.033)$ for plasma glucose during the OGTT indicating that the pattern of responses to the different diets varied significantly over the course of the study. At 3 months unadjusted 2hPCG did not differ significantly from baseline on any diet, but the change on Low-CHO was significantly smaller than that on High-GI by $1.26(0.22,2.30) \mathrm{mmol} / 1 \quad(p<0.05)$ (ESM Fig. 1). However, by 12 months $2 \mathrm{hPCG}$ had risen significantly from baseline on both the High-GI and Low-CHO diets by $1.41(0.37,2.45)$ and $1.33(0.29,2.37) \mathrm{mmol} / \mathrm{l}$, respectively $(p<0.05)$. The increase in $2 \mathrm{hPCG}$ at 12 months on Low-GI, $0.37(-0.63,1.37) \mathrm{mmol} / \mathrm{l}$, was not significant from baseline and was $1.06(0.02,2.10) \mathrm{mmol} / \mathrm{l}$ less than that a

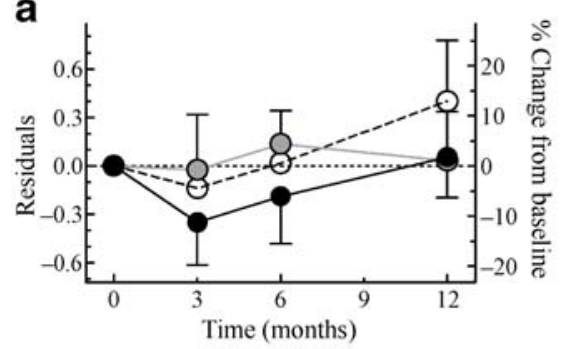

d

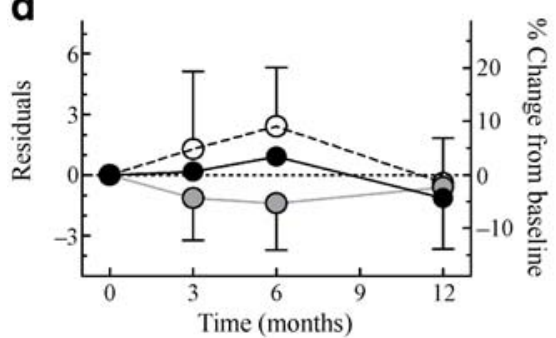

b

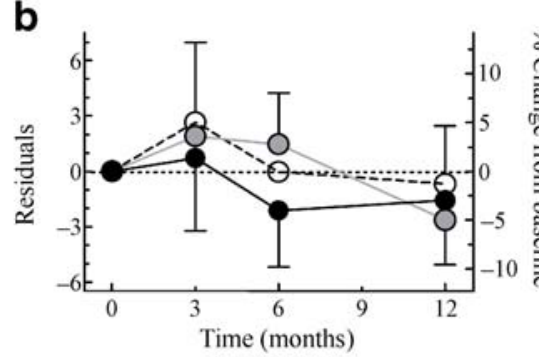

e

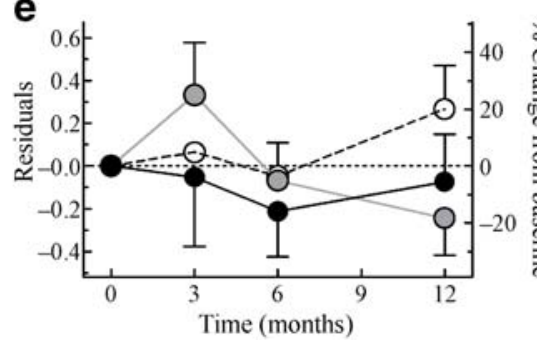

C

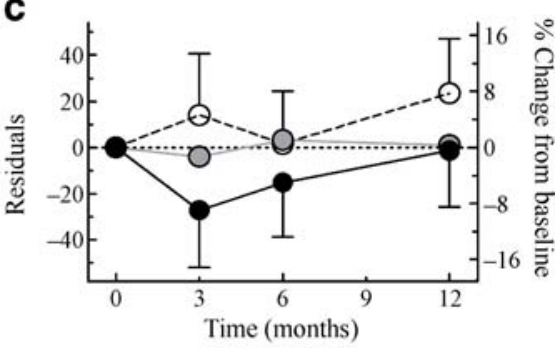

f

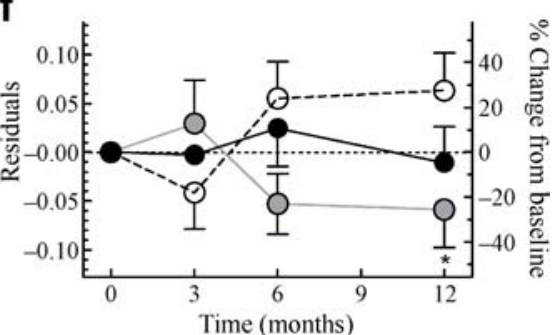

Fig. 1 Residuals of a HOMA-r, b HOMA-b, c HIR, d insulinogenic index, e muscle insulin sensitivity index and $\mathbf{f}$ disposition index, after adjustment for baseline value and sex in participants on High-GI (black circles, $n=41$ ), Low-GI (white circles, $n=46$ ) and Low-CHO (grey circles, $n=48$ ) diets. Values are means \pm SEM. (f) $* p<0.05$ for difference between Low-GI and Low-CHO; $p=0.036$ for time $\times$ treatment interaction 
on High-GI $(p<0.05)$ (ESM Fig. 1). There were no significant differences among diets for plasma insulin.

Insulin sensitivity, insulin secretion and disposition index There was no significant effect of time (3-12 months), diet, or time $\times$ diet interaction, respectively, for the residuals of HOMA-r ( $p=0.25, p=0.72, p=0.83)$, HOMA-b ( $p=0.40$, $p=0.91, p=0.96)$, HIR $(p=0.71, p=0.59, p=0.95)$, insulinogenic index $(p=0.78, p=0.77, p=0.94)$ or muscle insulin sensitivity index ( $p=0.37, p=0.67, p=0.38)$ (Fig. 1). However, a time $\times$ diet interaction was seen for MIS $\times$ II $(p=$ 0.036). Initially, the overall mean for MIS $\times$ II tended to be higher on Low-CHO than on Low-GI by $0.07(-0.04,0.18)$ $\mathrm{h}^{-1}$, but by the end of the study, the reverse was seen and MIS $\times$ II was $0.12(0.01,0.23) \mathrm{h}^{-1}$ higher on Low-GI than on Low-CHO $\left(p<0.05\right.$, pooled baseline value $\left.0.23 \mathrm{~h}^{-1}\right)$, with the value for High-GI being intermediate (Fig. 1).

The use of aspirin, NSAIDs, nutritional supplements or statins did not significantly affect the response of MIS $\times$ II to the Low-GI compared with the Low-CHO diet. In the 126 participants for whom data on drug use was available, the significance of the time $\times$ diet interaction for MIS $\times$ II, adjusted for baseline and sex, was $p=0.013$; this $p$ value was unchanged after additional adjustment for use of aspirin, NSAID, nutritional supplements or statins during the trial. Regardless of whether participants were taking these drugs or not, the residuals for MIS $\times$ II after 12 months on Low-GI always tended to be greater than those on LowCHO (ESM Table 2).

Changes $(\Delta)$ in $2 \mathrm{hPCG}$ were not significantly related to $\triangle$ HOMA-r, $\triangle$ HOMA-b or $\triangle$ HIR at any time. $\triangle 2 \mathrm{hPCG}$ was related to $\Delta$ muscle insulin sensitivity index at 3,6 and 12 months ( $r=-0.463,-0.466$ and -0.502 respectively, $p<$ 0.0001 for all). $\Delta 2 \mathrm{hPCG}$ was significantly related to
$\Delta$ insulinogenic index at $6(r=-0.204, p=0.017)$ and 12 months $(r=-0.194, p=0.024)$, but not at 3 months $(r=-0.092) . \Delta 2 \mathrm{hPCG}$ was related to $\Delta \mathrm{MIS} \times \mathrm{II}$ at 3,6 and 12 months ( $r=-0.577,-0.592$ and -0.579 respectively, $p<$ $0.0001)$. The correlations between $\triangle 2 \mathrm{hPCG}$ and $\triangle \mathrm{MIS} \times \mathrm{II}$ were greater than those between $\triangle 2 \mathrm{hPCG}$ and $\Delta$ insulinogenic index $(p<0.05)$, and were non-significantly greater than those between $\triangle 2 \mathrm{hPCG}$ and $\Delta$ muscle insulin sensitivity index (Fig. 2).

\section{Discussion}

Our results show that, in type 2 diabetic patients treated by diet alone, the short-term ( 3 months) changes in OGTT and disposition index resulting from changes in dietary carbohydrate intake did not reflect the longer term (1 year) results. In fact, the short-term effects were misleading, because the diet with the most beneficial effects on OGTT and disposition index after 3 months (Low-CHO) had the most deleterious effect after 12 months, whereas the diet with the most deleterious effect after 3 months (Low-GI) had the most beneficial effect after 12 months. The results also suggest that changes in OGTT are more closely related to changes in disposition index than to changes in insulin sensitivity or plasma insulin concentrations.

The overall goal of the treatment of diabetes is to prevent long-term micro- and macro-vascular complications. To this end, improving glycaemic control, as assessed by $\mathrm{HbA}_{1 \mathrm{c}}$, is considered important $[16,17]$. Thus, since we failed to show any significant difference in $\mathrm{HbA}_{1 \mathrm{c}}$ among diets, the clinical relevance of the present study has been questioned [18]. However, it is becoming apparent that $\mathrm{HbA}_{1 \mathrm{c}}$ is not the only relevant marker of risk for complications,
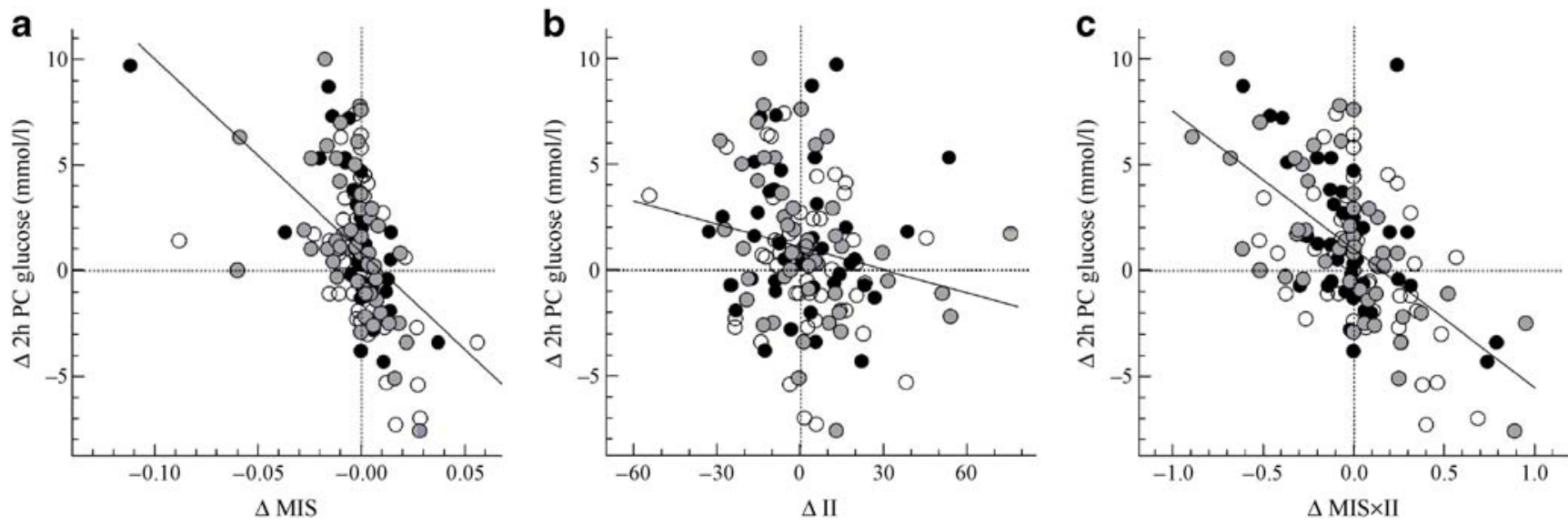

Fig. 2 Correlations between the changes (12 months-baseline) of $2 \mathrm{hPCG}$ and changes (12 months-baseline) in a muscle insulin sensitivity index (MIS) $(r=-0.504, p<0.0001)$, b insulinogenic index
(II) $(r=-0.194, p=0.024)$ and (c) disposition index (MIS $\times$ II $)(r=$ $-0.579, p<0.0001$ ) for individual participants on High-GI (black circles), Low-GI (white circles) and Low-CHO (grey circles) diets 
particularly with respect to risk of CVD in type 2 diabetes. In the United Kingdom Prospective Diabetes Study, treating type 2 diabetes with insulin, sulfonylureas or metformin reduced $\mathrm{HbA}_{1 \mathrm{c}}$ and microvascular complications to a similar extent, but only metformin reduced macrovascular complications $[19,20]$. Repaglinide therapy was associated with greater regression of carotid artery atherosclerosis than glibenclamide (known as glyburide in the USA and Canada), despite no difference in $\mathrm{HbA}_{1 \mathrm{c}}$ [21], while glibenclamide therapy for 4 years was associated with significantly fewer cardiovascular events than rosiglitazone, despite higher $\mathrm{HbA}_{1 \mathrm{c}}$ at the end of the study ( $0.076 \mathrm{vs}$ $\sim 0.070$ ) [22]. More recently, the intensive-treatment arm in the Action to Control Cardiovascular Risk in Diabetes study, which aimed to reduce $\mathrm{HbA}_{1 \mathrm{c}}$ to less than 0.06 , was stopped because of increased mortality [23]. While these studies question the value of aggressive pharmacological therapy to reduce $\mathrm{HbA}_{1 \mathrm{c}}$ in type 2 diabetes, their results may not be relevant to dietary management. Nevertheless, there is evidence that postprandial glucose, and not necessarily the level of $\mathrm{HbA}_{1 \mathrm{c}}$ achieved, is associated with increased risk of cardiovascular complications [24] and mortality [25], and with increased oxidative stress [26] in patients with type 2 diabetes. The latter finding is consistent with the significant reductions in postprandial glucose and C-reactive protein that we found in the present study in participants on the Low-GI, but not in those on the LowCHO diet [1]. Thus, the reduction in 2hPCG observed by us on the low-glycaemic-index diet could be clinically important as marking reduced CVD risk even in the absence of a difference in $\mathrm{HbA}_{1 \mathrm{c}}$.

Our results suggest that the changes observed by us in 2hPCG may be due to changes in disposition index, as a measure of beta cell function. Deterioration of disposition index appears to be the pathophysiological mechanism responsible for the development [3-5] and progression [5, 6] of type 2 diabetes; treatments which improve disposition index may, therefore, prevent type 2 diabetes or slow its progression. It is less clear whether poor beta cell function predisposes to the development of CVD, at least in part, because published reports from studies that have the relevant information have focused mainly on the relationship between insulin sensitivity and CVD without reporting the effects of beta cell function [27]. However, some studies suggest that impaired beta cell function, assessed as HOMA-b [28], insulinogenic index [29] or increased plasma proinsulin concentrations [30], is associated, independently, with increased CVD risk and/or mortality rate.

We used muscle insulin sensitivity index and insulinogenic index as indirect indices, estimated from OGTT, of insulin sensitivity and insulin secretion to calculate disposition index (here MIS $\times$ II). Our results need to be interpreted with caution for a number of reasons. Muscle insulin sensitivity index and insulinogenic index were validated against the euglycaemic clamp and intravenous glucose infusion, respectively, in individuals with normal or impaired glucose tolerance but not diabetes [12, 14]. Therefore, we cannot be sure they are valid in patients with type 2 diabetes. Nevertheless, the relationship between insulinogenic index and muscle insulin sensitivity index values at baseline in our participants, plotted by quartile of MIS $\times$ II, were, as expected, hyperbolic curves which became closer to the origin as the disposition index became smaller (ESM Fig. 2). Muscle insulin sensitivity index and insulinogenic index are indirect measures that rely on a number of assumptions, such as the rate and amount of glucose absorbed from the gut, which may not hold in our population. In addition, we did not take as many blood samples at baseline and during the OGTT as did AbdulGhani et al. [12], so our estimates may be less accurate or precise. Nevertheless, we did detect a significant time $\times$ treatment interaction for MIS $\times$ II. Also, our results are consistent with those of several previous studies showing that low-glycaemic-index starchy foods improve beta cell function or insulin secretion in persons without diabetes [10, 31].

On Low-GI it took 6 to 12 months for the increase in disposition index to become evident. We speculate this may be due to increased glucagon-like peptide-1 secretion stimulated by the short-chain fatty acids produced by fermentation of the increased load of starch entering the colon after low-glycaemic-index compared with highglycaemic-index foods [32]. Because of the complexity of the colonic ecosystem, short-chain fatty acid production may take 4 to 6 months to rise to a steady-state level after increased intake of resistant starch or fibre [33, 34] or acarbose therapy [35]. In animals, a high-fibre diet was shown to increase glucagon-like peptide-1 secretion [36], which, in turn, may increase beta cell mass or improve glucose sensing [37].

The reduction in $2 \mathrm{hPCG}$ and trend toward increased muscle insulin sensitivity index on Low-CHO at 3 months is consistent with short-term studies suggesting that LowCHO diets improve insulin sensitivity in type 2 diabetes [7, 8]. Since exchanging saturated fat for MUFA does not improve insulin sensitivity if total fat intake is $>37 \%$ energy [38], the short-term effect of low-carbohydrate/high-MUFA diets on insulin sensitivity may be due to reduced glucose toxicity resulting from lower postprandial glucose. However, our results suggest that Low-CHO meals did not continue to elicit low glycaemic responses in the long term [1]; the reason for this finding is unknown, but it is consistent with the progressive deterioration of disposition index on the Low-CHO diet between 3 and 12 months (Fig. 1). By contrast, the low glycaemic impact of Low-GI meals was sustained and even after 1 year was exactly predicted by the difference in meal glycaemic load [1]. 
Common drugs may affect glucose tolerance [39-43] or be used for conditions associated with insulin resistance, such as hypertension [44]; thus, the effect of diet on glucose metabolism may be modified by the use of drugs. In our population, use of aspirin, NSAIDs, nutritional supplements and statins was associated with differences in indices of carbohydrate metabolism at baseline. Nevertheless, the relative effects of the diets on disposition index did not appear to be influenced significantly by the use of these drugs. However, the study was not powered to investigate the interaction between diet and drugs, and because of the small number of participants in each diet/drug group, the 95\% CIs were large and the power to detect such effects was small.

In conclusion, our results suggest that, in patients with type 2 diabetes on diet alone, use of a Low-GI diet for 1 year increases disposition index, an index of beta cell function, compared with a low-carbohydrate/high-MUFA diet. This hypothesis will require further testing before it can be accepted as proven.

Acknowledgements This study was supported by the Canadian Institutes of Health Research (CIHR-MCT-44205). The following donated key foods for use in the study: Kellogg Canada, Robin Hood (division of Smucker Foods of Canada), HJ Heinz, Italpasta, Uncle Ben's Rice (division of Mars), Kraft Foods, Dainty Foods (division of MRRM), the Almond Board of California and the National Peanut Board.

Duality of interest T. M. S. Wolever has declared that he (1) is President and part-owner of Glycemic Index Laboratories, a contract research organisation; (2) is President and part-owner of Glycaemic Index Testing, a corporation that provides services related to the measurement of the glycaemic index of foods; (3) has received grant/ research support from Cargill and ILSI Europe; (4) is a consultant for McCain Foods; (5) is a stock shareholder in Ceapro; and (6) has received honoraria for consulting/speaking from the Dutch Sugar Bureau, Mars, and Institut Benjamin Delessert. T. M. S. Wolever is co-author of a range of popular books on the glycaemic index under the general title of 'The glucose revolution: authoritative guide to the glycemic index' (Marlowe, NY); he is also author of a scientific book entitled: 'The glycaemic index: a physiological classification of dietary carbohydrate' (CABI, UK). All other co-authors declare that there is no duality of interest associated with this manuscript.

\section{References}

1. Wolever TMS, Gibbs AL, Mehling C et al (2008) The Canadian trial of Carbohydrates in Diabetes (CCD), a 1-y controlled trial of low-glycemic-index dietary carbohydrate in type 2 diabetes: no effect on glycated hemoglobin but reduction in C-reactive protein. Am J Clin Nutr 87:114-125

2. Kahn SE, Prigeon RL, McCulloch DK et al (1993) Quantification of the relationship between insulin sensitivity and B cell function in human subjects. Evidence for a hyperbolic function. Diabetes 42:1663-1672
3. Kahn SE (2003) The relative contribution of insulin resistance and beta-cell function to the pathophysiology of type 2 diabetes. Diabetologia 46:3-19

4. Weyer C, Bogardus C, Mott DM, Pratley RE (1999) The natural history of insulin secretory dysfunction and insulin resistance in the pathogenesis of type 2 diabetes mellitus. J Clin Invest 104:787-794

5. Festa A, Williams K, D'Agostino R Jr, Wagenknecht LE, Haffner SM (2006) The natural course of b-cell function in nondiabetic and diabetic individuals: The Insulin Resistance Atherosclerosis Study. Diabetes 55:1114-1120

6. UK Prospective Diabetes Study Group (1995) UK Prospective diabetes study 16. Overview of 6 years' therapy of type II diabetes: a progressive disease. Diabetes 44:1249-1258

7. Garg A, Grundy SM, Unger RH (1992) Comparison of effects of high and low carbohydrate diets on plasma lipoproteins and insulin sensitivity in patients with mild NIDDM. Diabetes 41:1278-1285

8. Parillo M, Rivellese AA, Ciardullo AV et al (1992) A highmonounsaturated-fat/low-carbohydrate diet improves peripheral insulin sensitivity in non-insulin-dependant diabetic patients. Metabolism 41:1373-1378

9. Rizkalla SW, Taghrid L, Laromiguiere M et al (2004) Improved plasma glucose control, whole-body glucose utilization, and lipid profile on a low-glycemic index diet in type 2 diabetic men: a randomized trial. Diabetes Care 27:1866-1872

10. Wolever TMS, Mehling C (2002) High-carbohydrate/low-glycaemic index dietary advice improves glucose disposition index in subjects with impaired glucose tolerance. Brit J Nutr 87:477-487

11. Matthews DR, Hosker JP, Rudenski AS, Naylor BA, Treacher DF, Turner RC (1985) Homeostasis model assessment: insulin resistance and b-cell function from fasting plasma glucose and insulin concentrations in man. Diabetologia 28:412-419

12. Abdul-Ghani MA, Matsuda M, Balas B, DeFronzo RA (2007) Muscle and liver insulin resistance indexes derived from the oral glucose tolerance test. Diabetes Care 30:89-94

13. Stumvoll M, Mitrakou A, Pimenta W et al (2000) Use of the oral glucose tolerance test to assess insulin release and insulin sensitivity. Diabetes Care 23:295-301

14. Phillips DI, Clark P, Hales C, Osmond C (1994) Understanding oral glucose tolerance: comparison of glucose or insulin measurements during the oral glucose tolerance test with specific measurements of insulin resistance and insulin secretion. Diabetic Med 11:286-292

15. Cody RP, Smith JK (1997) Applied statistics and the SAS programming language, 4th edn. Prentice Hall, Upper Saddle River

16. Diabetes Control and Complications Trial Research Group (DCCT) (1993) The effect of intensive treatment of diabetes on the development and progression of long-term complications in insulin-dependent diabetes mellitus. New Engl J Med 329:977-986

17. Nathan DM, Cleary PA, Backlund JY et al (2005) Intensive diabetes treatment and cardiovascular disease in patients with type 1 diabetes. New Engl J Med 353:2643-2653

18. Pi-Sunyer X (2008) Glycemic index in early type 2 diabetes. Am J Clin Nutr 87:3-4

19. UK Prospective Diabetes Study Group (1998) Effect of intensive blood-glucose control with metformin on complications in overweight patients with type 2 diabetes (UKPDS 34). Lancet 352:854-865

20. UK Prospective Diabetes Study Group (1998) Intensive bloodglucose control with sulfonylureas or insulin compared with conventional treatment and risk of complications in patients with type 2 diabetes (UKPDS 33). Lancet 352:837-853

21. Esposito K, Giugliano D, Nappo F et al (2004) Regression of carotid atherosclerosis by control of postprandial hyperglycemia in type 2 diabetes mellitus. Circulation 110:214-219 
22. Kahn SE, Haffner SM, Heise MA et al (2006) Glycemic durability of rosiglitazone, metformin, or glyburide monotherapy. New Engl J Med 355:2427-2443

23. US Dept. of Health and Human Services (2008) For safety, NHLBI changes intensive blood sugar treatment strategy in clinical trial of diabetes and cardiovascular disease. Available from http://www.nih.gov/news/health/feb2008/nhlbi-06.htm, accessed 25 February 2008

24. Decode study group on behalf of the European Diabetes Epidemiology Group (1999) Glucose tolerance and mortality: comparison of WHO and American diabetes association diagnostic criteria. Lancet 354:617-621

25. Hanefeld M, Fischer S, Julius U et al (1996) Risk factors for myocardial infarction and death in newly detected NIDDM: the Diabetes Intervention Study, 11-year follow-up. Diabetologia 39:1577-1583

26. Monnier L, Mas E, Ginet C et al (2006) Activation of oxidative stress by acute glucose fluctuations compared with sustained chronic hyperglycemia in patients with type 2 diabetes. JAMA 295:1681-1687

27. Howard G, O’Leary DH, Zaccaro D et al (1996) Insulin sensitivity and atherosclerosis. The Insulin Resistance Atherosclerosis Study (IRAS) Investigators. Circulation 93:1809-1817

28. Nóvoa FJ, Boronat M, Saavedra P et al (2005) Differences in cardiovascular risk factors, insulin resistance, and insulin secretion in individuals with normal glucose tolerance and in subjects with impaired glucose regulation: The Telde study. Diabetes Care 28:2388-2393

29. Wallander M, Bartnick M, Efendic S et al (2005) Beta cell dysfunction in patients with acute myocardial infarction but without previously known type 2 diabetes: a report from the GAMI study. Diabetologia 48:2229-2235

30. Alssema M, Dekker JM, Nijpels G, Stehouwer CDA, Bouter LM, Heine RJ (2005) Proinsulin concentration is an independent predictor of all-cause and cardiovascular mortality. Diabetes Care 28:860-865

31. Laaksonen DE, Toppinen LK, Juntunen KS et al (2005) Dietary carbohydrate modification enhances insulin secretion in persons with the metabolic syndrome. Am J Clin Nutr 82:1218-1227

32. Wolever TMS, Jenkins DJA, Vuksan V et al (1992) Beneficial effect of a low-glycaemic index diet in type 2 diabetes. Diabet Med 9:451-458

33. Le Blay G, Michel C, Blottière HM, Cherbut C (1999) Enhancement of butyrate production in the rat caecocolonic tract by long-term ingestion of resistant potato starch. Brit J Nutr $82: 419-426$

34. Wolever TMS, Schrade KB, Vogt JA, Tsihlias EB, McBurney MI (2002) Could colonic short chain fatty acids contribute to longterm adaptation of blood lipids on a high fiber diet in subjects with type 2 diabetes. Am J Clin Nutr 75:1023-1030

35. Wolever TMS, Radmard R, Chiasson J-L et al (1995) One-year acarbose therapy raises fasting serum acetate in diabetic patients. Diabetic Med 12:164-172

36. Reimer RA, McBurney MI (1996) Dietary fiber modulates intestinal proglucagon messenger ribonucleic acid and postprandial secretion of glucagon-like peptide-1 and insulin in rats. Endocrinology 137:3948-3956

37. Baggio LL, Drucker DJ (2007) Biology of incretins: GLP-1 and GIP. Gastroenterology 132:2131-2157

38. Vessby B, Uusitupa M, Hermansen K et al (2001) Substituting dietary saturated for monounsaturated fat impairs insulin sensitivity in healthy men and women: the KANWU study. Diabetologia 44:312-319

39. Paolisso G, Gambardella A, Verza M, D'Amore A, Sgambato S, Varricchio M (1992) ACE inhibition improves insulin-sensitivity in aged insulin-resistant hypertensive patients. J Hum Hypertension 6:175-179

40. Black HR, Davis B, Barzilay J et al (2008) Metabolic and clinical outcomes in nondiabetic individuals with the metabolic syndrome assigned to chlorthalidone, amlodipine, or lisinopril as initial treatment for hypertension: a report from the Antihypertensive and Lipid-Lowering Treatment to Prevent Heart Attack Trial (ALLHAT). Diabetes Care 31:353-360

41. Mohlig M, Freudenberg M, Bobbert T et al (2006) Acetylsalicylic acid improves lipid-induced insulin resistance in healthy men. $\mathrm{J}$ Clin Endocrinol Metab 91:964-967

42. Fogari R, Preti P, Lazzari P et al (2006) Effects of amlodipineatorvastatin combination on inflammation markers and insulin sensitivity in normocholesterolemic obese hypertensive patients. Eur J Clin Pharmacol 62:817-822

43. Kaaja R, Kujala S, Manhem K et al (2007) Effects of sympatholytic therapy on insulin sensitivity indices in hypertensive postmenopausal women. Int J Clin Pharmacol Ther 45:394401

44. DeFronzo RA, Ferrannini E (1991) Insulin resistance: a multifaceted syndrome responsible for NIDDM, obesity, hypertension, dyslipidemia, and atherosclerotic cardiovascular disease. Diabetes Care 14:173-194 